\title{
The Differences in Social Comparison of Adolescent Girls During the COVID-19 Pandemic in Terms of the Duration of Instagram Social Media Use
}

\author{
Natalia Natalia ${ }^{1}$ Agustina Agustina ${ }^{1 *}$ \\ ${ }^{1}$ Faculty of Psychology, Universitas Tarumanagara, Jakarta 11440, Indonesia \\ ${ }^{*}$ Corresponding author. Email: agustina@fpsi.untar.ac.id
}

\begin{abstract}
Social comparison is the idea that individuals determine their own social and personal value based on how they compare themselves to others. Based on a survey conducted by Watson [16], it is known that during the COVID-19 pandemic, the duration of social media use which includes Instagram increased by $44 \%$. Prolonged usage of Instagram can lead to social comparison behavior, especially among women who often compare themselves with others [6]. The purpose of this study is to determine whether there were differences in social comparisons among female adolescents during the COVID-19 pandemic in terms of the duration of Instagram use. This study involved 393 female adolescent participants aged 13 to 22 years who actively use Instagram, gathered using purposive sampling method. The results showed that there was no difference in social comparisons among girls during the COVID-19 pandemic in terms of the duration of Instagram use. However, after further data processing, it is known that one of the dimensions of social comparison, namely the ability dimension, has a significant difference, while the opinion dimension has the opposite result.
\end{abstract}

Keywords: social comparison, ability, opinion, duration, social media, Instagram, adolescents

\section{INTRODUCTION}

Until now, January 2, 2021, more than 82 million people in the world have been infected with COVID-19 and more than 758 thousand Indonesians have been infected with COVID-19 [16]. During the pandemic due to the spread of the COVID-19 virus, several changes have occurred. These changes include the community having to implement distancing, economic downturns, most systems becoming online, and the emergence of the fear of being infected with COVID-19 [7]. Several changes have also occurred in Indonesia, including people being required to wear masks and wash their hands with soap and running water [2].

Based on the results of a survey conducted online from 16 to 20 March 2020, it was found that the duration of social media use such as Instagram, Facebook, and Twitter increased by $44 \%$ worldwide during the COVID-19 pandemic [19]. The use of social media may lead to its users perceiving that other people's lives are better than theirs [15]. According to Yuheng et al. (2014), People who are using Instagram Social Media most likely using this social media to promote themselves and build a connection with their friends. According to the results of research conducted by Yuheng et al. [20] about Instagram content analysis, that the content uploaded by Instagram users the most is content related selfies, and content about their friends. Hwang [5] stated that social media users tend to worry about other people's impressions of themselves, so they create impressions that match their desires. They upload only the best photos of themselves and give off the impression that they are having fun with their friends and family [5]. So that Instagram users compares themselves with other users that who are considered better than themselves. Hwang [5] stated that Instagram allows us to make new friends, therefore, Instagram is the ideal platform for social comparisons. Verduyn et al. [14] said that the concern about social comparison behavior through social media arose because it has never happened before on such a level and scale as in recent times, which may have a negative impact on the subjective well-being (SWB) of social media users.

Social comparison can occur offline when someone interacts with their closest people such as colleagues and family [15]. Social comparison is the idea that individuals determine their own social and personal values based on how they compare themselves to others [4]. Vogel et al. [15] stated that the increasing use of social media has caused the information used to conduct social comparisons to be obtained through social media. Social media provides an opportunity for its users to make social comparisons, because social media provides complete information about other people [15]. This can affect the self-esteem and self-evaluation of social media users which occurs because of social comparisons [15]. 
According to research on the importance of the role of social media in social comparison, social comparison is positively associated with depression [5].

Furthermore, research on the relationship between social media, social comparisons and self-esteem of female participants showed that the duration of social media use affects upward and downward social comparison behavior [15]. Active use of Instagram by looking at the latest status, comments, photos, and videos of other Instagram users is strongly related to social comparison behavior [5]. Jabłońska and Zajdel [6] stated that the effect of prolonged usage of Instagram can cause someone to conduct social comparisons, especially women who often compare their appearance with others.

Based on the results of research on the effects of social media on social comparisons and envy in adolescents conducted by Charoensukmongkol [3], it is known that the duration of social media use has a strong positive relationship with social comparisons conducted by adolescents. Adolescents often use their peers as a reference in conformity, a reference in self-evaluation and a reference in social comparison [12]. Basically, adolescents often compare themselves with their peers or it can be said that teenagers often make social comparisons with their peers [10]. Adolescents who are exposed to content from their peers who want to impress other people through uploads on their social media, can easily trigger social comparison behavior based on what they see from what their peers' upload [3]. Adolescents constantly compare themselves to other people they see on social media, and this can damage their self-esteem [10]. Based on the explanation of several experts above, it can be said that adolescents, especially girls, tend to conduct social comparisons, especially with their peers. Therefore, the researchers set female adolescents as the subject of this study.

\subsection{Our Contribution}

The theoretical contribution of this research includes contribution towards social psychology, education, and developmental psychology of adolescents. This includes knowledge about differences in social comparisons among adolescents during the COVID-19 pandemic based on the duration of Instagram usage. This study can also serve as the basis for further research on differences in social comparisons among adolescents based on the duration of Instagram use.

Practically, this research can serve as positive input for teenagers to be wiser in using Instagram. This research is also useful for parents of teenagers. Parents can control the duration of adolescent social media use, so that adolescents can avoid the adverse effects of social comparison behavior, especially during the pandemic.

\subsection{Paper Structure}

This paper consists of five parts. The first part deals with the background of the research problem. The second part is a theoretical review, which consists of theories relating to the duration of Instagram usage and social comparison. The third part is about the research method. The fourth part is the results and analysis of research data. The fifth part contains the conclusions of the results of this study.

\section{BACKGROUND}

\subsection{Social Comparison}

Social comparison is the idea that individuals determine their own social and personal value based on how they compare themselves to others [4]. Festinger [4] divides social comparison into two types or directions, which are upward social comparison and downward social comparison. Upward social comparison is a comparison made by an individual with another individual who are considered better than themselves [4]. Downward social comparison is a comparison made by an individual with another individual who is considered lower than themselves [4].

Social comparison has two dimensions, namely opinion and ability [4]. The opinion dimension is the opinion of oneself regarding what one think and feel about others. Meanwhile, the dimension of ability is a comparison of the individual with others in terms of their skills. Comparison of skills is conducted by looking at what other people possess in terms of competence, ability, or popularity. According to Festinger [4], there are three things that influence social comparison, namely self-evaluation, selfenhancement, and self-improvement. Meanwhile, according to Stiles and Kaplan [18], a person can be influenced by low self-esteem or stress to conduct a social comparison.

\subsection{Duration of Instagram Social Media Use}

Pasarow [19] conducted a survey regarding the duration of Instagram usage in one day, based on the average usage in the past week. This survey involved 33 participants who use Instagram. Based on the survey results, it was found that 6 participants used Instagram for less than 30 minutes per day, 13 participants used Instagram for 30 to 60 minutes per day, 9 participants used Instagram for 60 to 120 minutes per day, while 5 participants used Instagram for more than 120 minutes per day. Based on this data, the average duration of Instagram usage can be determined, which is 72 minutes per day. Therefore, this study uses the results of the survey as a reference to determine differences in the duration of Instagram usage.

\section{RESEARCH METHOD}

The study participants based on the background described above consisted of young girls aged 13 to 22 years. The age range was chosen because Instagram social media users are at least 13 years old. Research participants must have at least 1 Instagram account and actively use that 
account every day for the past week prior to data collection. The sampling technique used in this research is purposive sampling technique. This study involved 393 participants.

This study uses comparative quantitative research technique to test the research hypothesis. This research was conducted online, by distributing research questionnaires through social media. This was done to reduce physical contact with participants, in order to prevent the spread of the COVID-19 virus.

The social comparison measurement instrument used in this study is the Iowa-Netherlands Comparison Orientation Scale Measure (INCOM) compiled by Gibbons and Buunk [17]. The measuring instrument consists of 11 items that contain statements about comparing oneself with others. These statements can be responded to with five response options ranging from 1 to 5 . The measuring instrument that will be distributed to research participants has been adapted into Indonesian by Amelia [1]. The process of adapting the measuring instrument is done through validity and reliability testing, with the results of the adapted measuring instrument being valid and the item reliability value of 0.821 , so it is considered highly reliable. Therefore, the adapted measuring tool is viable.

The duration of Instagram use was measured by including a question regarding the duration of Instagram use in the questionnaire. The questionnaire was compiled based on a survey previously conducted by Pasarow [9]. In this question, the authors used four groups of duration of Instagram use, which are less than 30 minutes per day, coded as 1, 30 to 60 minutes per day which is coded as 2, 60 to 120 minutes per day which is coded as 3 , and more than 120 minutes per day coded as 4 .

\section{FINDINGS AND DISCUSSIONS}

The normality test in this research was conducted using the Kolmogorov-Smirnov test method using SPSS software. It is known that the results of data processing obtained a social comparison significance value of 0.00 (< 0.05 ), so it can be said that the distribution of data is not normally distributed and the data of this study is nonparametric.

Hypothesis testing used Kruskal-Wallis analysis, because the data is not normally distributed. The result shows that there is no significant difference between the social media use duration groups with $\mathrm{H}=3.882$ and $\mathrm{p}$ value. $=0.274$ (>0.05).

Another factor that contributes to there being no difference in social comparisons among adolescent girls during the COVID-19 pandemic in terms of the duration of Instagram use in this study is that there are other factors that play a role in social comparison. There are many other factors that influence and contribute to social comparison behavior. According to Festinger [4], there are three factors that may influence social comparison, namely selfevaluation, self-improvement and self-improvement. Meanwhile, according to Stiles and Kaplan [18], other factors that can affect social comparison are low selfesteem and when we get stressed.

Researchers conducted an analysis of differences in social comparisons among female adolescents during the COVID-19 pandemic on each dimension of the social comparison measurement tool, namely the dimension of ability and the dimension of opinion. Analysis of each dimension of the social comparison measurement tool with Kruskal-Wallis was conducted with the Instagram social media usage groups (less than 30 minutes per day, 30 to 60 minutes per day, 60 to 120 minutes per day, and more than 120 minutes per day). The results of the ability dimension showed that there were significant differences between the four groups, with $\mathrm{H}=9,853, \mathrm{p}=0.020$ ( $<0.05$ ). Meanwhile, the result of the opinion dimension shows that there is no significant difference between the four groups, with $\mathrm{H}=2.469$, and $\mathrm{p}$ value $=0.481(>0.05)$.

The reason why only the ability dimension has a significant difference in this study is because according to research conducted by Noon [8] involving 266 adolescents regarding the influence of social comparisons on the formation of adolescent personality, it was found that social comparisons of abilities and opinions have different psycho-emotional consequences towards Instagram users. Instagram users tend to do ability social comparisons because content on Instagram encourages feelings of inadequacy and anxiety in teens. This feeling of inadequacy led to adolescents making upward social comparisons by comparing themselves with other Instagram users they consider better than themselves. Meanwhile, the opinion dimension is found to be positively related to feelings of optimism and inspiration. This study has several limitations that can affect the results of this study, because it was conducted during the COVID19 pandemic. Researchers must prioritize the application of health protocols applicable in Indonesia. Therefore, this research can only be done online, to reduce physical contact with participants. This led to the researchers having less control over the data collection process. This research was also conducted in less than six months, leading to the results not being optimal. The data collection time took only one month. Therefore, the researchers decided not to conduct a test on social comparison measuring instrument in a foreign language, but instead use a measuring instrument that had previously been tested by other researchers. This is because researchers want to maximize data collection time. Researchers do not give any limits to the content that can be accessed by the participants, so that the researchers do not know about the content that can be triggers social comparison.

\section{CONCLUSIONS}

After the hypothesis test conducted by the researchers, it can be concluded that there is no significant difference in social comparisons among adolescent girls during the COVID-19 pandemic in terms of the duration of Instagram use. Based on the results of additional data analysis that 
has been carried out on each dimension of social comparison, it is known that in the opinion dimension there is no significant difference in adolescents during the COVID-19 pandemic in terms of the duration of use of social media Instagram. However, there are significant differences in other dimensions of social comparison, namely the dimensions of ability in adolescents during the COVID-19 pandemic in terms of the duration of use of Instagram social media.

\section{ACKNOWLEDGMENT}

This work was supported by Faculty of Psychology, Universitas Tarumanagara, Jakarta 11440, Indonesia.

\section{REFERENCES}

[1] Amelia, G. A. (2019). Pengaruh social comparison terhadap life satisfaction pada remaja akhir yang menggunakan Instagram. Universitas Negeri Jakarta, Jakarta

[2] Andayani, T. R. (2020). Sumber informasi serta dampak penerapan pembatasan sosial dan fisik pada masa pandemi COVID-19: Studi eksploratif di Indonesia. Psikologi Sosial, 18(59). https://doi.org/10.7454/jps.2020.xx

[3] Charoensukmongkol, P. (2018). The impact of social media on social comparison and envy in teenagers: The moderating role of the parent comparing children and in-group competition among friends. Journal of Child and Family Studies, 27(1), 69-79. https://doi.org/10.1007/s10826-017-0872-8

[4] Festinger, L. (1954). A theory of social comparison processes. In Human Relations (Vol. 7, Issue 2).

[5] Hwang, H. S. (2019). Why social comparison on instagram matters: Its impact on depression. KSII Transactions on Internet and Information Systems, 13(3), 1626-1638. https://doi.org/10.3837/tiis.2019.03.029

[6] Jabłońska, M. R., \& Zajdel, R. (2020). Artificial neural networks for predicting social comparison effects among female Instagram users. PLoS ONE, $15(2)$, $1-18$. https://doi.org/10.1371/journal.pone.0229354

[7] McGowan, M. L., Norris, A. H., \& Bessett, D. (2020). Mental health and the Covid-19 pandemic. The
New England Journal of Medicine, 383(6), 508-510. https://doi.org/10.1056/NEJMp2013466

[8] Noon, E. J. (2020). Compare and despair or compare and explore? Instagram social comparisons of ability and opinion predict adolescent identity development. Cyberpsychology, 14(2). https://doi.org/10.5817/CP2020-2-1

[9] Pasarow, A. (2019). We Asked 33 People How Much Time They Spend on Instagram Every Day. Rifenery29. https://www.refinery29.com/en-us/howmuch-time-do-you-spend-on-instagram\#: :text=An unofficial poll of 33,than two hours a day.

[10] Putra, J. S. (2018). Peran syukur sebagai moderator pengaruh perbandingan sosial terhadap selfesteem pada remaja pengguna media sosial. Psikohumaniora: Jurnal Penelitian

[11] Psikologi, 3(2), 197. https://doi.org/10.21580/pjpp. v3i2.2650

[12] Santrock, J. W. (2016). Adolescence (16th ed.). In McGraw-Hill.

[13] Schneider, S. (2011). the Comparison Orientation Scale by Gibbons Buunk.

[14] Verduyn, P., Gugushvili, N., Massar, K., Täht, K., \& Kross, E. (2020). Social comparison on social networking sites. Current Opinion in Psychology, 36, 32-37. https://doi.org/10.1016/j.copsyc.2020.04.002

[15] Vogel, E. A., Rose, J. P., Roberts, L. R., \& Eckles, K. (2014). Social comparison, social media, and selfesteem. Psychology of Popular Media Culture, 3(4), 206-222. http://eds.a.ebscohost.com/eds/pdfviewer/ pdfviewer?vid=2\&sid=4237ac28-97d8-412c-bbdc2b79d6ed7523@sessionmgr4002\&hid=4211

[16] Watson, A. (2020). In-home media consumption due to the coronavirus outbreak among internet users worldwide as of March 2020, by country. Statista.Com. https://www.statista.com/statistics/1106498/homemedia-consumption-coronavirus-worldwide-bycountry/\#: :text=A global survey conducted in,due to the COVID-19

[17] Schneider, S. (2011). the Comparison Orientation Scale.

[18] Stiles, B. L., \& Kaplan, H. B. (2004). Adverse social comparison processes and negative self-feelings: A test of alternative models. Social Behavior and Personality, 32(1), 31-44. https://doi.org/10.2224/sbp. 2004.32.1.31 
[19] WHO. (2021). WHO Coronavirus Disease (COVID-19) Dashboard. WHO.Int. https://covid19. who.int/?gclid=EAIaIQobChMIlsaTz_Dl6wIVSKaWC h1EoAHaEAAYASAAEgK9avD_BwE

[20] Yuheng, H., Lydia, M., \& Subbarao, K. (2014). A first analysis of Instagram photo content and user types. Frontiers of Mathematics in China, 12(1), 247-260. https:// www.aaai.org/ocs/index.php/ICWSM/ICWSM 14/paper/view/8118/8087 